\title{
The Role of Bronchoscopic Findings and Bronchoalveolar Lavage Fluid Cytology in Early Diagnosis of Ventilator-Associated Pneumonia
}

\author{
Pavlos Vernikos PhD MD, Christos F Kampolis PhD MD, \\ Konstantinos Konstantopoulos PhD MD, Apostolos Armaganidis PhD MD, and \\ Petros Karakitsos PhD MD
}

\begin{abstract}
BACKGROUND: Early diagnosis of ventilator-associated pneumonia (VAP) is necessary to reduce morbidity and improve survival of critically ill patients in the ICU. The purpose of the present study is to examine the performance of macroscopic bronchoscopic findings and cytological analysis of bronchoalveolar lavage fluid (BALF) as an early diagnostic tool for VAP, either alone or in combination with clinically oriented scores (modified Clinical Pulmonary Infection Score [CPIS] or Johanson criteria). METHODS: BAL was performed in $\mathbf{5 4}$ consecutive mechanically ventilated subjects. The predictive value of isolated or combined clinical characteristics, BALF, and/or other laboratory measurements in diagnosing VAP was analyzed by logistic regression analysis. A separate diagnostic score was derived from a linear combination of independent variables included in the multivariate model and compared with CPIS, Johanson criteria, and their combinations with BALF cytology (receiver operating characteristic curve analysis). RESULTS: Integrating relative neutrophil cell count in CPIS or Johanson criteria optimized their specificity ( $>80 \%)$ but decreased sensitivity $(<70 \%)$. Radiographic progression and the presence of distal purulent secretions on bronchoscopy were independently associated with VAP diagnosis. A new score that incorporates clinical, radiographic, and early bronchoscopic findings presented excellent diagnostic accuracy (area under curve $=\mathbf{0 . 9 6}$, sensitivity $94.3 \%$, specificity $84.2 \%$ ). CONCLUSIONS: The diagnostic performance of classical clinical scores for VAP did not improve after combination with BALF cytology. A new composite score proved to be more accurate than previous scores in early VAP diagnosis. Key words: bronchoscopy; bronchoalveolar lavage (BAL); ventilator-associated pneumonia (VAP); mechanical ventilation; clinical pulmonary infection score (CPIS); Johanson criteria. [Respir Care 2016;61(5):658-•. (C) 2016 Daedalus Enterprises]
\end{abstract}

\section{Introduction}

Ventilator-associated pneumonia (VAP) is a well-known complication affecting up to $27 \%$ of mechanically venti- lated patients. It accounts for approximately $25 \%$ of all ICU-acquired infections and for $>50 \%$ of all antibiotic use in ICU patients. ${ }^{1}$ VAP prolongs ICU stay and mechanical ventilation and increases costs of hospitalization. Overall mortality ranges between 20 and $50 \%$ and may reach

The authors have disclosed no conflicts of interest.

Correspondence: Christos F Kampolis MD, Intensive Care Unit, Laiko General Hospital, 17 Ag. Thoma str, 11527 Athens, Greece. E-mail: chkamp77@gmail.com.

DOI: $10.4187 /$ respcare. 04265 
$70 \%$ in patients with VAP and immunosuppression and/or multidrug-resistant infections, whereas VAP-attributable mortality approximates $30 \% .^{2}$ Besides pathogen virulence and host defense response, inappropriate or delayed initial antimicrobial therapy are factors associated with increased mortality. 3,4

Many clinical entities, such as alveolar hemorrhage, drug-induced lung toxicity, cardiogenic pulmonary edema, primary or secondary ARDS, collagen vascular diseases, and primary or metastatic lung cancer may mimic lower respiratory tract infections, but they differ from VAP in terms of management and overall prognosis. ${ }^{5}$ However, no single clinical symptom or sign, imaging, or microbiological test can be used for the accurate early diagnosis of VAP. In addition, histopathology and/or tissue cultures is the most accepted, but not uniformly accepted, standard. ${ }^{6}$ Several combinations of criteria related to clinical manifestations, radiology techniques, and/or bacteriological data derived from bronchoalveolar specimens have been proposed for the diagnosis of VAP. The criteria introduced in 1972 by Johanson et al ${ }^{7}$ included clinical and radiographic variables but had moderate sensitivity, specificity, and accuracy $(69,75$, and $72 \%$, respectively) when compared with immediate postmortem lung biopsies. ${ }^{8}$ More recently, the Clinical Pulmonary Infection Score (CPIS) was reported by Pugin et $\mathrm{al}^{9}$ as a new surrogate clinical marker for VAP. Despite the fact that sensitivity and specificity of CPIS for VAP diagnosis were high (93 and 100\%, respectively) in the original publication, which was based on a small study population $(N=28),{ }^{9}$ subsequent studies concluded that the score performed moderately compared with either pathological diagnosis or bronchoalveolar lavage fluid (BALF)-established diagnosis. ${ }^{2,10}$ At present, the most routinely utilized clinical criteria for VAP are those developed and recently updated by the United States Centers for Disease Control and Prevention (CDC). ${ }^{11}$

Fiberoptic bronchoscopy is a useful, albeit interventional, diagnostic modality that offers the potential for direct inspection of bronchial mucosa and respiratory secretions and for obtaining microbiological samples by using protected specimen brushing and/or bronchoalveolar lavage (BAL). Microbiological (quantitative and semiquantitative) analyses of specimens and recovery of a microorganism in sufficient quantity from the lower airways outweigh the lack of specificity associated with pure clinical diagnostic approaches to VAP. On the other hand, VAP diagnosis may be delayed for up to $48-72 \mathrm{~h}$ pending BALF cultures. In this context, direct (within 2-3 h) cytologic examination of BALF may serve as an adjunct to a clinical approach for early diagnosis of VAP. The aim of the present study is to examine the performance of macroscopic bronchoscopic findings and cytological analysis of BALF as an early diagnostic tool for VAP, either alone or in combination

\section{QUICK LOOK}

\section{Current knowledge}

Ventilator-associated pneumonia (VAP) accounts for $\sim 25 \%$ of all ICU-acquired infections and $>50 \%$ of all antibiotic use in ICU patients. Early diagnosis of VAP cannot rely on a single clinical symptom or sign, imaging, or microbiological test. The average diagnostic performance of scores based on combinations of clinical and/or radiographic criteria (eg, modified Clinical Pulmonary Infection Score [CPIS] or Johanson criteria) is moderate and varies among different studies.

\section{What this paper contributes to our knowledge}

Integrating relative neutrophil cell count in modified CPIS or Johanson criteria optimized their specificity but decreased sensitivity to poor levels. Radiographic progression and presence of distal purulent secretions on bronchoscopy were the only independent early recognizable factors significantly associated with VAP diagnosis. A new diagnostic score, which incorporated clinical (duration of mechanical ventilation, presence of immunosuppression), radiographic, and early bronchoscopic findings (purulence of distal secretions), presented excellent diagnostic accuracy for VAP compared with either Johanson criteria or modified CPIS.

with clinically oriented scores, such as the CPIS or Johanson criteria. ${ }^{7}$

\section{Methods}

\section{Subjects}

Bronchoscopy with BAL was performed in consecutive mechanically ventilated subjects admitted to the ICU of Laiko General Hospital for acute respiratory failure, as indicated by deteriorating respiratory function (a significant decrease in $\mathrm{P}_{\mathrm{aO}_{2}}$ and/or an increase in $\mathrm{P}_{\mathrm{aCO}}$ ) and new onset or worsening pathology of plain chest radiograph and/or computed tomography (consolidation, infiltrates, pleural effusion, or atelectasis). The following variables were recorded for each subject: sex, age, comorbidities such as COPD and immunosuppression, total stay in the ICU, APACHE II (Acute Physiology and Chronic Health Evaluation II) score on ICU admission, length of intubation period, body temperature, presence or absence of shock, complete blood count, and treatment with antibiotics and/or antifungal agents at the time of bronchoscopy. The study received the approval of the Ethics Committee of Laiko General Hospital. 


\section{Bronchoscopy}

Intravenous boluses of midazolam or propofol were administered to provide sedation during bronchoscopy. The BAL procedure was carried out by instillation and recovery of 5-7 $20-\mathrm{mL}$ aliquots of sterile $0.9 \%$ normal saline solution. Wedge position was decided on the basis of radiology findings (radiograph and/or computed tomograph), whereas right middle lobe or lingula were preferred in subjects with diffuse pulmonary infiltrates or inconclusive radiology. BALF recovery was $\geq 40-50 \mathrm{~mL}$ in all cases.

Fluid recovered from the first $20-\mathrm{mL}$ aliquot was handled as a bronchial washing specimen, since it contains a greater proportion of bronchial epithelial cells, and was cultured for common pathogens and mycobacteria. Subsequent aliquots were considered to be more representative BALF specimens. Two of them were placed in specific Cytolyt solution containers and were sent to the cytology laboratory within the first 2-3 h after bronchoscopy. At least one additional BALF specimen was stained and cultured for common pathogens or examined after specific stains (eg, acid-fast stain, Grocott methenamine silver stain, immunofluorescence). BALF cytology included differential cell counts and investigation for possible specific diagnoses, such as alveolar hemorrhage, primary or metastatic pulmonary malignancy, common or specific lung infections (eg, caused by Pneumocystis jirovecii, cytomegalovirus, or mycobacteria), or pulmonary manifestations of a systemic disease (eg, sarcoidosis, collagen vascular disease). In subjects with a clinical suspicion of diffuse alveolar hemorrhage and increased number of hemosiderin-laden macrophages in BALF, the Golde score was calculated, as originally defined by Golde et al. ${ }^{12}$ A Golde score of $>100$ was considered to indicate severe diffuse alveolar hemorrhage, whereas a score between 20 and 100 was considered mild to moderate. In addition, direct or indirect signs of malignancy from direct inspection of the bronchial tree, macroscopic appearance of distal secretions surging from segmental bronchial inlets (serous, mucous, purulent, and/or bloody), bronchial mucosal edema, or friability were recorded as well.

\section{VAP Definitions and Clinical Scores}

The updated definition of VAP provided by the CDC/National Healthcare Safety Network (PNU2) ${ }^{11}$ was used as the accepted standard when comparing the performance of different definitions and scores in early diagnosis of VAP. The examined definitions were the commonly used Johanson clinical criteria (Definition A), the modified CPIS $(>6)$ (Definition B), ${ }^{13}$ and new definitions originating from the combination of Definitions A and B with different neutrophil differential (\%) cell count cutoff values $(20-80 \%)$ in BALF analysis (Definitions C and $\mathrm{D}$, respectively) or from the linear combination of various independent variables and covariates included in the multivariate analysis described below in the Statistical Analysis section (Definition E).

\section{Statistical Analysis}

Non-parametric methods (Mann-Whitney or KruskalWalis) were used for the comparison of continuous variables, since distribution was not normal for most variables and sample size was relative small. The appropriate parametric (chi-square test) or non-parametric method (Fisher exact test) was selected for the comparison of unranked categorical variables among different subject groups. The non-parametric Kendall's tau test was performed to measure the correlation between two ranked variables.

The predictive value of isolated or combined clinical characteristics and/or BAL and/or other laboratory measurements in diagnosing VAP was analyzed by univariate or multivariate logistic regression models. A separate clinical score was calculated for each subject from a linear combination of independent variables and covariates included in the multivariate model. More specifically, the coefficients used for the calculation of the score were the same as the respective $\beta$ coefficients (or equivalently the $\log$ odds ratios), as estimated in the multivariable analysis. A receiver operating characteristic curve analysis was then used to determine the optimal cutoff value for the new score (Definition E) and for the proposed VAP Definitions C and D. Sensitivity, specificity, positive and negative predictive values, and correct classification rates were calculated for each VAP definition (A-E).

The statistical package STATA 10 (StataCorp, College Station, Texas) was used for analyses. A statistical association was considered significant if the $P$ value was $<.05$.

\section{Results}

Fifty-four consecutive subjects ( 31 males/23 females), with a median age of 72 y (interquartile range $58-80 \mathrm{y}$ ), were finally included in the study and underwent bronchoscopy with BAL. The reasons for initial ICU admission were as follows: severe pulmonary infection $(n=18)$, sepsis/multi-organ failure $(n=11)$, extubation failure in the early postoperative period $(n=9)$, acute cardiac events $(n=10)$, and coma $(n=6)$. Thirty-five subjects were finally diagnosed as having VAP according to the updated definition of VAP provided by the CDC/National Healthcare Safety Network, whereas worsening of respiratory function in the remaining subjects was caused by ARDS $(n=4)$, acute cardiac failure $(n=3)$, atelectasis $(n=5)$, alveolar hemorrhage $(n=2), P$. jiroveci infection $(n=2)$, cytomegalovirus infection $(n=1)$, uremic lung $(n=1)$, 
Table 1. Clinical and Laboratory Characteristics of ICU Subjects on the Day of Bronchoscopy

\begin{tabular}{|c|c|c|c|c|}
\hline & Total $(N=54)$ & $\operatorname{VAP}(n=35)$ & Non-VAP $(n=19)$ & $P$ \\
\hline Female sex, $n(\%)$ & $23(42.6)$ & $12(34.3)$ & $11(57.9)$ & .17 \\
\hline Age, median (IQR) y & $72(58-80)$ & $73(62-80)$ & $64(54-80)$ & .15 \\
\hline COPD, $n(\%)^{*}$ & $10(18.5)$ & $9(25.7)$ & $1(5.3)$ & .08 \\
\hline Immunosuppression, $n(\%)$ & $16(29.6)$ & $9(25.7)$ & $7(36.8)$ & .58 \\
\hline Duration of mechanical ventilation, median (IQR) d & $16(8-36)$ & $20(9-37)$ & $13(3-23)$ & .27 \\
\hline \multicolumn{5}{|l|}{ Cause of admission in ICU, $n(\%)$} \\
\hline Severe pulmonary infection & $18(33.3)$ & $13(37.1)$ & $5(26.3)$ & .62 \\
\hline Sepsis/multi-organ failure* & $11(20.4)$ & $7(20.0)$ & $4(21.1)$ & $>.99$ \\
\hline Extubation failure in the early postoperative period* & $9(16.7)$ & $6(17.1)$ & $3(15.8)$ & $>.99$ \\
\hline Acute cardiac events* & $10(18.5)$ & $5(14.3)$ & $5(26.3)$ & .46 \\
\hline Coma* & $6(11.1)$ & $4(11.4)$ & $2(10.5)$ & $>.99$ \\
\hline Fever, median (IQR) ${ }^{\circ} \mathrm{C}$ & $38.5(37.8-38.8)$ & $38.6(38.2-38.8)$ & $38.2(37.4-38.7)$ & .037 \\
\hline Shock, $n(\%)$ & $30(55.6)$ & $20(57.1)$ & $10(52.6)$ & $>.99$ \\
\hline Peripheral WBC, median $(\mathrm{IQR}) \times 10^{3}$ & $10.7(7.4-17.5)$ & $11.3(7.4-17.5)$ & $8.6(7.4-21.3)$ & .53 \\
\hline New or progressive consolidation/infiltrates, $n(\%)^{*}$ & $44(81.5)$ & $34(97.1)$ & $10(52.6)$ & $<.001$ \\
\hline APACHE II score, median (IQR) & $21(16-26)$ & $20(15-26)$ & $22(17-24)$ & .72 \\
\hline CPIS, median (IQR) & $6(5-7)$ & $7(6-8)$ & $5(4-7)$ & $<.001$ \\
\hline Antibiotic therapy, $n(\%)^{*}$ & $50(92.6)$ & $33(94.3)$ & $17(89.5)$ & .61 \\
\hline \multicolumn{5}{|l|}{ No. of antibiotics prescribed, $n(\%)$} \\
\hline $1 *$ & $8(14.8)$ & $4(11.4)$ & $4(21.1)$ & .43 \\
\hline 2 & $30(55.6)$ & $21(60.0)$ & $9(47.4)$ & .54 \\
\hline $3^{*}$ & $10(18.5)$ & $8(22.9)$ & $2(10.5)$ & .31 \\
\hline $4 *$ & $2(3.7)$ & $0(0)$ & $2(10.5)$ & .12 \\
\hline Antifungal agents, $n(\%)$ & $19(35.2)$ & $11(31.4)$ & $8(42.1)$ & .62 \\
\hline Treatment for Pneumocystis jirovecii, mycobacteria, or viruses, $n(\%)^{*}$ & $8(14.8)$ & $2(5.7)$ & $6(31.6)$ & .02 \\
\hline Final outcome (mortality), $n(\%)$ & $33(61.1)$ & $23(65.7)$ & $10(52.6)$ & .52 \\
\hline \multicolumn{5}{|l|}{$\begin{array}{l}\text { * Fisher exact test. } \\
\text { VAP }=\text { ventilator-associated pneumonia } \\
\text { IQR }=\text { interquartile range } \\
\text { WBC }=\text { white blood cells } \\
\text { APACHE II }=\text { Acute Physiology and Chronic Health Evaluation II } \\
\text { CPIS = Clinical Pulmonary Infection Score }\end{array}$} \\
\hline
\end{tabular}

and disseminated intravascular coagulation $(n=1)$. Subjects with VAP had higher median CPIS and median body temperature compared with subjects with another diagnosis, as shown in Table 1.

Table 2 demonstrates the macroscopic bronchoscopic findings and the results of cytological and microbiological analyses of BALF. The persistence of purulent distal secretions surging from segmental bronchial inlets was more frequent in subjects with VAP $(P<.001)$. As expected from the definition of VAP, the rate of isolation of any pathogen was higher in the VAP group $(P<.001)$. The most frequently isolated pathogens were Pseudomonas aeruginosa and Acinetobacter baumannii. On the contrary, macroscopic findings of inflammation (eg, bronchial mucosal edema or friability) were more prevalent in subjects without $\operatorname{VAP}(P=.038)$.

The presence or absence of VAP was treated as a dichotomous dependent variable in a univariate logistic regression analysis, whereas the clinical and laboratory parameters included in Tables 1 and 2 were the examined independent variables. New onset or progressive deterioration of preexisting consolidation and/or lung infiltrates on chest radiograph or computed tomograph (odds ratio [OR] 30.60; 95\% CI 3.45-271.51), BALF culture positivity (OR 58.29; 95\% CI 6.48-524.04), and the persistent presence of purulent distal secretions surging from segmental bronchial inlets (OR 58.29; 95\% CI 6.48-524.04) were the only statistically significant factors associated with VAP in univariate analysis $(P=.002,<.001$ and $<.001$, respectively) (Table 3 ). A multivariate analysis was then performed, including radiological progression as defined previously; the presence of purulent distal secretions on bronchoscopy; duration of mechanical ventilation, which is a known risk factor for $\mathrm{VAP}^{2}$; and the presence or absence of immunosuppression (see Table 4). The new score generated from the linear combination of independent variables and covariates included in the multivariate model was named RPDMI (radiological progression, purulent secretions, duration of mechanical ventilation, immunosuppression). The RPDMI score was calculated 
Table 2. Macroscopic Bronchoscopic Findings and Bronchoalveolar Lavage Fluid Cytology and Microbiology Results

\begin{tabular}{|c|c|c|c|c|}
\hline & Total $(N=54)$ & $\operatorname{VAP}(n=35)$ & Non-VAP $(n=19)$ & $P$ \\
\hline \multicolumn{5}{|l|}{ Macroscopic findings, $n(\%)$} \\
\hline Indicative of malignancy* & $4(7.4)$ & $2(5.7)$ & $2(10.5)$ & .61 \\
\hline Indicative of acute inflammation* & $11(20.4)$ & $4(11.4)$ & $7(36.8)$ & .038 \\
\hline Macroscopic appearance of distal secretions, $n(\%)$ & & & & $<.001$ \\
\hline Serous & $2(3.7)$ & $1(2.9)$ & $1(5.3)$ & \\
\hline Mucous & $8(14.8)$ & $0(0)$ & $8(42.1)$ & \\
\hline Purulent & $39(72.2)$ & $32(91.4)$ & $7(36.8)$ & \\
\hline Bloody & $3(5.6)$ & $0(0)$ & $3(15.8)$ & \\
\hline Purulent + bloody & $2(3.7)$ & $2(5.7)$ & $0(0)$ & \\
\hline \multicolumn{5}{|l|}{ Cytological examination of BALF } \\
\hline Indicative of acute inflammation, $n(\%)^{* \dagger}$ & $42(77.8)$ & $29(82.9)$ & $13(68.4)$ & .31 \\
\hline \multicolumn{5}{|l|}{ Cell count, median (IQR) \% } \\
\hline Alveolar macrophages & $17.5(0-30)$ & $10.0(0-30)$ & $27.5(7.5-40)$ & .15 \\
\hline Neutrophils & $58(30-80)$ & $60.0(30-80)$ & $50.0(20-80)$ & .53 \\
\hline Lymphocytes & $10(0-10)$ & $10.0(2-10)$ & $7.5(0-10)$ & .38 \\
\hline \multicolumn{5}{|l|}{ BALF microbiology positive for, $n(\%)^{*}$} \\
\hline Pseudomonas aeruginosa & $12(22.2)$ & $10(28.6)$ & $2(10.5)$ & .18 \\
\hline Acinetobacter baumannii & $12(22.2)$ & $12(34.3)$ & $0(0)$ & .004 \\
\hline Pseudomonas + Acinetobacter & $6(11.1)$ & $5(14.3)$ & $1(5.3)$ & .41 \\
\hline Klebsiella pneumoniae & $2(3.7)$ & $2(5.7)$ & $0(0)$ & .54 \\
\hline Staphylococus aureus & $2(3.7)$ & $2(5.7)$ & $0(0)$ & .54 \\
\hline Serratia marcensens & $1(1.9)$ & $1(2.9)$ & $0(0)$ & $>.99$ \\
\hline Cytomegalovirus & $1(1.9)$ & $0(0)$ & $1(5.3)$ & $>.99$ \\
\hline Pneumocystis jiroveci & $2(3.7)$ & $0(0)$ & $2(10.5)$ & .12 \\
\hline Any microrganism & $41(75.9)$ & $34(97.1)$ & $7(36.8)$ & $<.001$ \\
\hline \multicolumn{5}{|l|}{$\begin{array}{l}\text { * Fisher exact test. } \\
\dagger \text { Defined as a differential neutrophil count }>5 \% . \\
\text { VAP }=\text { ventilator-associated pneumonia } \\
\text { BALF = bronchoalveolar lavage fluid } \\
\text { IQR = interquartile range }\end{array}$} \\
\hline
\end{tabular}

by the equation: $\mathrm{RPDMI}=7.9 \times$ radiological progression $+8.4 \times$ purulent secretions $+.064 \times$ duration of mechanical ventilation in days $-2.89 \times$ immunosuppression. The presence of each of radiological progression, purulent secretions, or immunosuppression scored 1 point, whereas duration of mechanical ventilation was handled as a continuous variable.

The accuracy of RPDMI for early diagnosis of VAP was excellent according to the area under the receiver operating characteristic curve (AUC) $(0.96,95 \%$ CI $0.87-$ $0.96)$ with an optimal combination of sensitivity $(94.3 \%$, 95\% CI 88.1-100\%) and specificity (84.2\%, 95\% CI $74.5-93.9 \%$ ) at a cutoff value of 14.1 (Definition E). On the other hand, the corresponding diagnostic accuracy was good for Definition B (AUC: 0.80, 95\% CI 0.67-0.93), fair for Definition C (AUC: 0.78, 95\% CI 0.65-0.89), and poor for Definition D (AUC: 0.68 , 95\% CI 0.53-0.80) (Fig. 1). Sensitivity, specificity, positive and negative predictive values, and correct classification rate $(\%)$ for the early diagnosis of VAP were calculated for each of the 5 aforementioned proposed definitions (A-E) (Table 5).
Incorporating the effect of relative neutrophil cell count (\%) (at various cutoff values) in Definitions C and D increased specificity at the expense of sensitivity. Definition $\mathrm{C}$ including a $20 \%$ cutoff value offered the best combination of sensitivity $(67.6 \%, 95 \%$ CI 54.7-80.6\%) and specificity $(81.3 \%, 95 \%$ CI $70.4-92.1 \%)$.

\section{Discussion}

The diagnosis of VAP is made when a patient who has been mechanically ventilated for $\geq 48 \mathrm{~h}$ develops a new or progressive infiltrate, and the respiratory specimens are positive. However, VAP cannot be confirmed or ruled out until the completion of culture results, which generally takes 2-3 d. Furthermore, pure clinical approaches, such as modified CPIS and Johanson criteria, are characterized by a wide variance in sensitivity and specificity among different studies and a relatively moderate overall performance in early VAP diagnosis. Our study questioned the possible role of early bronchoscopic (macroscopic or cytologic) findings as a separate diagnostic tool or as an 


\section{BRONCHOSCOPY AND BAL IN EARLY Diagnosis OF VAP}

Table 3. Results From Univariate Logistic Regression Model for the Probability of Ventilator-Associated Pneumonia

\begin{tabular}{|c|c|c|c|}
\hline & OR & $95 \% \mathrm{CI}$ & $P$ \\
\hline Sex (male/female) & 0.38 & $0.12-1.20$ & .10 \\
\hline Age (per 10 y of increase) & 1.40 & $0.94-2.09$ & .09 \\
\hline COPD (yes/no) & 6.23 & $0.72-53.58$ & .10 \\
\hline Immunosuppression (yes/no) & 0.59 & $0.18-1.97$ & .40 \\
\hline Duration of mechanical ventilation (per $30 \mathrm{~d}$ of increase) & 0.95 & $0.60-1.51$ & .84 \\
\hline \multicolumn{4}{|l|}{ Cause of admission in ICU (yes/no)* } \\
\hline Sepsis/multi-organ failure & 0.67 & $0.14-3.35$ & .63 \\
\hline Extubation failure in the early postoperative period & 0.77 & $0.14-4.33$ & .77 \\
\hline Acute cardiac events & 0.38 & $0.08-1.93$ & .25 \\
\hline Coma & 0.77 & $0.11-5.61$ & .80 \\
\hline Fever (per $1^{\circ} \mathrm{C}$ increase) & 2.36 & $0.98-5.70$ & .056 \\
\hline Shock (yes/no) & 1.20 & $0.39-3.69$ & .75 \\
\hline Peripheral WBC (log 10) (per $1 \log -10)$ & 1.53 & $0.21-11.07$ & .67 \\
\hline New or progressive consolidation/infiltrates (yes/no) & 30.60 & $3.45-271.51$ & .002 \\
\hline APACHE II Score (per 5 units increase) & 0.89 & $0.56-1.42$ & .62 \\
\hline CPIS (per 1 unit increase) & 2.31 & $1.37-3.91$ & .002 \\
\hline Antibiotic therapy (yes/no) & 1.94 & $0.25-15.01$ & .53 \\
\hline \multicolumn{4}{|l|}{ Bronchoscopic findings } \\
\hline Purulent distal secretions (yes/no) & 58.29 & $6.48-524.04$ & $<.001$ \\
\hline BALF cytology indicative of acute inflammation (yes/no) & 2.23 & $0.60-8.24$ & .23 \\
\hline Positive BALF culture (yes/no) & 58.29 & $6.48-524.04$ & $<.001$ \\
\hline \multicolumn{4}{|l|}{ BALF cell count $(\%)$ (per $10 \%$ increase) } \\
\hline Alveolar macrophages & 0.84 & $0.66-1.08$ & .18 \\
\hline Neutrophils & 1.07 & $0.87-1.32$ & .51 \\
\hline Lymphocytes & 1.35 & $0.59-3.10$ & .48 \\
\hline $\begin{array}{l}\text { * Fisher exact test. } \\
\text { OR = odds ratio } \\
\text { WBC = white blood cells } \\
\text { APACHE II = Acute Physiology and Chronic Health Evaluation II } \\
\text { CPIS = Clinical Pulmonary Infection Score } \\
\text { BALF = bronchoalveolar lavage fluid }\end{array}$ & & & \\
\hline
\end{tabular}

Table 4. Results From Multivariate Logistic Regression Model for the Probability of Ventilator-Associated Pneumonia

\begin{tabular}{|c|c|c|c|c|}
\hline & $\beta$ Coefficient (log OR) & OR & $95 \% \mathrm{CI}$ & $P$ \\
\hline Immunosuppression (yes/no) & -2.891 & 0.06 & $0.00-0.90$ & .042 \\
\hline Duration of mechanical ventilation (per $30 \mathrm{~d}$ of increase) & 1.921 & 6.82 & $1.19-39.09$ & .031 \\
\hline New or progressive consolidation/infiltrates (yes/no) & 7.934 & $2,790.89$ & $5.68-1.4 \times 10^{6}$ & .01 \\
\hline Purulent distal secretions (yes/no) & 8.424 & $4,555.54$ & $7.34-2.8 \times 10^{6}$ & .01 \\
\hline $\begin{array}{l}\mathrm{VAP}=\text { ventilator-associated pneumonia } \\
\mathrm{OR}=\text { odds ratio }\end{array}$ & & & & \\
\hline
\end{tabular}

adjunct to preexisting clinical scores. Integrating relative neutrophil cell count in modified CPIS or Johanson criteria optimized their specificity $(>80 \%$ for all combinations) but decreased sensitivity to poor levels $(<60 \%$ for most combinations). Radiographic progression (pulmonary consolidation and/or infiltrates) and presence of distal purulent secretions on bronchoscopy were the only independent early recognizable factors significantly associated with VAP diagnosis. We herein propose a new diagnostic score, RPDMI, which incorporates clinical (duration of MV, pres- ence of immunosuppression), radiographic, and early bronchoscopic findings (purulence of distal secretions). An optimal cutoff value of 14.1 provides excellent accuracy (AUC $>0.9$ ) and higher sensitivity and specificity (94.3 and $84.2 \%$, respectively) compared with either Johanson criteria or modified CPIS.

In agreement with our results, several previous studies using BALF cultures or, more rarely, lung tissue histology and culture as the accepted standard showed that CPIS with a cutoff value of $6^{13-19}$ and Johanson criteria ${ }^{8}$ have a 


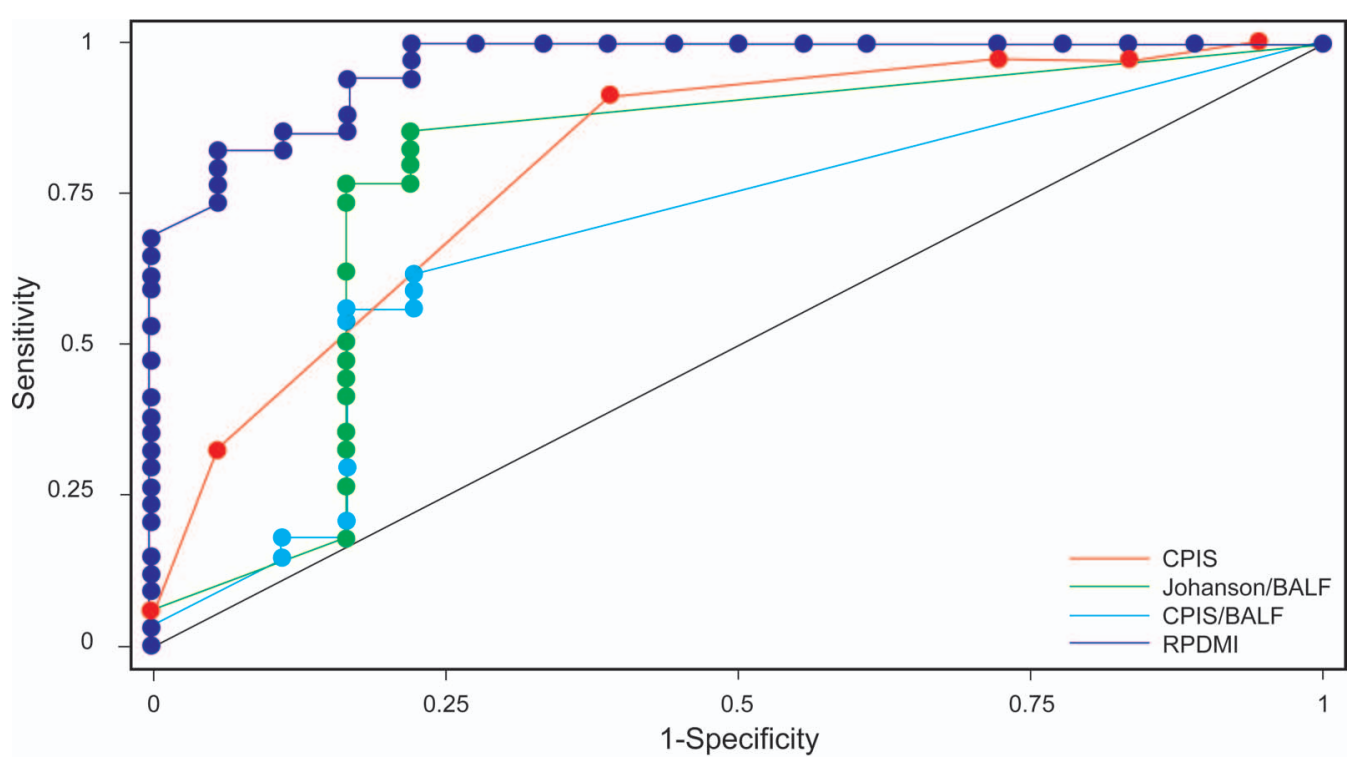

Fig. 1. Comparison of receiver operating characteristic curves illustrating the performance of modified Clinical Pulmonary Infection Score (area under the curve $=0.80$ ), Johanson criteria combined with BALF (area under the curve $=0.78$ ), modified CPIS combined with BALF (area under the curve $=0.68$ ), neutrophil cell count $(\%)$, and the newly proposed RPDMI score (area under the curve $=0.96$ ) in early diagnosis of ventilator-associated pneumonia. CPIS = modified Clinical Pulmonary Infection Score; BALF = bronchoalveolar lavage fluid; $\mathrm{RPDMI}=$ radiological progression, purulent secretions, duration of mechanical ventilation, immunosuppression.

low specificity $(\leq 80 \%)$ for VAP diagnosis. Furthermore, modified CPIS lacks sensitivity $(<80 \%)$, as described in the present and previous studies focusing on the simplified version of the CPIS. ${ }^{13,16-18}$ The relative neutrophil cell count $(\%)$ at various cutoff levels did not substantially improve the diagnostic performance of either modified CPIS or Johanson criteria. This result could be partially justified by the absence of a significant difference in neutrophil cell count between subjects with VAP and subjects with another diagnosis. Although most of the few previous studies focusing on the role of cellular profiles of BALF for the differential diagnosis between bacterial and viral pneumonia ${ }^{20}$ or pneumonia and other diagnoses ${ }^{21-23}$ concluded that bacterial pneumonia was associated with higher percentages of neutrophils in BALF, only 2 of these publications included subjects receiving mechanical ventilation, ${ }^{20,23}$ which may mildly increase BALF neutrophil count even in the absence of lung injury, ${ }^{24}$ and none of them focused on VAP. In the present study, among the 19 subjects without VAP, all 4 subjects with ARDS, 1 of 5 subjects with atelectasis, and all 3 subjects with acute cardiac failure had a percentage of neutrophil cell count in BALF $>50 \%$. Increased relative neutrophil cell counts (up to $50 \%$ ) have been observed previously in the early stages of $\operatorname{ARDS}^{25}$ and atelectasis ${ }^{26}$ and have been attributed to a possible mechanism of increased alveolar-capillary permeability. On the contrary, although prolonged mechanical ventilation per se may mildly increase BALF neutrophil cell count, this cannot completely explain the high neutrophil percentage in the 3 subjects with acute cardiac failure. All had clinical and/or radiographic deterioration, significantly elevated serum brain natriuretic peptide levels, and abnormal echocardiogram and improved after intense medical therapy for heart failure. Although high levels of relative neutrophil cell count (\%) may imply the co-existence of an underlying mechanism of acute lung injury, none of these subjects typically fulfilled the criteria for ARDS.

An important reason for the poor accuracy of existing clinical criteria (CPIS or Johanson) for diagnosing VAP could be the fact that purulent tracheobronchial secretions are also present in patients without VAP receiving mechanical ventilation or in patients with ventilator-associated tracheobronchitis. ${ }^{1,27,28}$ In addition, clinical signs, symptoms, and microbiologic criteria for evaluating endotracheal sputum aspirate samples included in the diagnostic criteria for ventilator-associated tracheobronchitis overlap with the criteria for VAP. However, ventilatorassociated tracheobronchitis does not involve pulmonary parenchyma and, thus, does not cause the progressive radiographic pulmonary infiltrates included in the VAP definition. ${ }^{29}$ Along the same lines as our findings, a previous bronchoscopic study by Timsit et $\mathrm{al}^{30}$ recognized the presence of distal purulent secretions, the persistence of distal secretions surging from distal bronchi during exhalation, and the decrease of $\mathrm{P}_{\mathrm{aO}_{2}} / \mathrm{F}_{\mathrm{IO}_{2}}$ for $\geq 50 \mathrm{~mm} \mathrm{Hg}$ as significant factors associated with a diagnosis of pneumonia in mechanically ventilated subjects; the presence of at least 2 factors had a sensitivity of $78 \%$ and a specificity of $89 \% .{ }^{30}$ The RPDMI score incorporates both factors of radiographic 
Table 5. Diagnostic Performance of Johanson Criteria, Modified CPIS, Their Combinations With Bronchoalveolar Lavage Fluid Cytology, and RPDMI Score in Ventilator-Associated Pneumonia Diagnosis

\begin{tabular}{|c|c|c|c|c|c|c|c|c|}
\hline \multirow{2}{*}{ VAP Definitions } & & \multicolumn{7}{|c|}{ Neutrophil Cell Count } \\
\hline & & $>20 \%$ & $>30 \%$ & $>40 \%$ & $>50 \%$ & $>60 \%$ & $>70 \%$ & $>80 \%$ \\
\hline \multicolumn{9}{|l|}{ A (Johanson criteria), \% } \\
\hline Sensitivity & 85.7 & & & & & & & \\
\hline Specificity & 73.7 & & & & & & & \\
\hline Positive predictive value & 85.7 & & & & & & & \\
\hline Negative predictive value & 73.7 & & & & & & & \\
\hline Correct classification rate & 81.5 & & & & & & & \\
\hline \multicolumn{9}{|l|}{ B (modified CPIS $>6$ ), \% } \\
\hline Sensitivity & 62.9 & & & & & & & \\
\hline Specificity & 73.7 & & & & & & & \\
\hline Positive predictive value & 81.5 & & & & & & & \\
\hline Negative predictive value & 51.9 & & & & & & & \\
\hline Correct classification rate & 66.7 & & & & & & & \\
\hline \multicolumn{9}{|c|}{$\begin{array}{l}\mathrm{C} \text { (Johanson criteria combined with different cutoff } \\
\text { values of relative neutrophil cell count), \% }\end{array}$} \\
\hline Sensitivity & & 67.6 & 58.8 & 50.0 & 47.1 & 35.3 & 26.5 & 17.6 \\
\hline Specificity & & 81.3 & 81.3 & 81.3 & 81.3 & 81.3 & 81.3 & 81.3 \\
\hline Positive predictive value & & 88.5 & 87.0 & 85.0 & 84.2 & 80.0 & 75.0 & 66.7 \\
\hline Negative predictive value & & 54.2 & 48.1 & 43.3 & 41.9 & 37.1 & 34.2 & 31.7 \\
\hline Correct classification rate & & 72.0 & 66.0 & 60.0 & 58.0 & 50.0 & 44.0 & 38.0 \\
\hline \multicolumn{9}{|c|}{$\begin{array}{l}\text { D (CPIS }>6 \text { combined with different cutoff values } \\
\text { of relative neutrophil cell count), } \%\end{array}$} \\
\hline Sensitivity & & 47.1 & 41.2 & 35.3 & 32.4 & 20.6 & 17.6 & 14.7 \\
\hline Specificity & & 81.3 & 81.3 & 81.3 & 81.3 & 81.3 & 87.5 & 87.5 \\
\hline Positive predictive value & & 84.2 & 82.4 & 80.0 & 78.6 & 70.0 & 75.0 & 71.4 \\
\hline Negative predictive value & & 41.9 & 39.4 & 37.1 & 36.1 & 32.5 & 33.3 & 32.6 \\
\hline Correct classification rate & & 58.0 & 54.0 & 50.0 & 48.0 & 40.0 & 40.0 & 38.0 \\
\hline \multicolumn{9}{|l|}{ E (RPDMI score), \% } \\
\hline Sensitivity & 94.3 & & & & & & & \\
\hline Specificity & 84.2 & & & & & & & \\
\hline Positive predictive value & 91.7 & & & & & & & \\
\hline Negative predictive value & 88.9 & & & & & & & \\
\hline Correct classification rate & 90.7 & & & & & & & \\
\hline $\begin{array}{l}\mathrm{VAP}=\text { ventilator-associated pneumonia } \\
\mathrm{CPIS}=\text { clinical pulmonary infection score } \\
\mathrm{RPDMI}=\text { radiological progression, purulent se }\end{array}$ & cal vent & , immunos & & & & & & \\
\hline
\end{tabular}

progression and distal purulent secretions, and this could possibly explain its better diagnostic accuracy compared with other purely clinical criteria.

It is of notice that subjects belonging in the VAP or non-VAP group (see Table 1 ) had similarly high mortality rates (65.7 and $52.6 \%$, respectively, $P=.52)$. This observation could be partially explained by the relatively high APACHE scores of subjects on ICU admission (median 20, interquartile range 15-26 and median 22, interquartile range $17-24$, respectively, $P=.72$ ), which have been associated with predicted death rates ranging from 40 to $50 \%$ in non-operative subjects. ${ }^{31,32}$ Unfortunately, our institutional admission policy is restricted to more severely ill patients due to limited ICU beds. We should also take into consideration the fact that the observed mortality rates among ICU patients who are transferred from other inpatient facilities may be even higher than those predicted by APACHE II (lead time bias). ${ }^{33}$ Moreover, it should be emphasized that our observational study exclusively aimed to identify isolated clinical and laboratory factors or clinical scores that best predict VAP and that assessing the possible impact of a novel therapeutic strategy based on RPDMI or other scores on mortality outcome was beyond the scope of this study.

We acknowledge some limitations of the present study. First, our accepted standard for VAP diagnosis was the definition provided by the CDC/National Healthcare Safety Network with microbiological evidence based solely on 
BALF analysis rather than histopathology and/or tissue culture results. However, isolation by culture from biopsy or autopsy lung specimens is usually difficult to obtain. Additionally, focal involvement of lung tissue by bacterial infection may result in negative cultures despite a histopathology compatible with acute inflammation, ${ }^{34,35}$ whereas interpretation of findings by different pathologists may present significant variation $(18-38 \%) .{ }^{6}$ It is also worth commenting on the excessively high ORs of the two variables (new or progressive infiltrates and purulent distal secretions) included in the multivariate analysis. Some possible explanations for these results are: (1) these two variables had very high ORs in the univariate analysis as well (30.6 and 58.3, respectively); (2) unlike linear regression models, ORs estimated from logistic regression analysis can easily become very high, since they are derived from exponentiation of the respective $\beta$ coefficients; and (3) the relatively small sample size, although more than adequate compared with other similar studies, cannot ensure stable and precise estimates. In particular, after a simple crosstabulation of VAP with these two variables, specific cells of the corresponding 2-way tables have very low frequencies. Nonetheless, the very high ORs still reflect the huge and well-known prognostic value of the respective clinical findings. Finally, the negative impact of the presence of immunosuppression on RPDMI score is another limitation of the present study. A possible explanation for this observation is that, in these subjects, early antibiotic modification is a common practice on the basis of a low clinical diagnostic threshold for VAP but may influence final microbiology results. However, the low number $(n=16)$ of immunosuppressed subjects included in our analysis makes it difficult to draw a definite conclusion for the role of RPDMI score in this category of critically ill patients.

\section{Conclusions}

This study did not substantiate any additive diagnostic value in VAP diagnosis by combining BALF cytology with classical pure clinical scores. On the other hand, a new score encompassing clinical and radiological characteristics and an early bronchoscopic finding (purulence of secretions from distant airways) presented excellent diagnostic accuracy. The utility of this diagnostic tool should be further evaluated in larger populations of mechanically ventilated patients, including those with immunosuppression. In addition, a randomized control trial would be very useful in assessing the possible impact of an RPDMI scorebased treatment approach on specific outcomes, such as mortality, ventilator-free days, total duration of ICU stay, and rationalization of antimicrobial use.

\section{REFERENCES}

1. American Thoracic Society, Infectious Diseases Society of America. Guidelines for the management of adults with hospital-acquired, ventilator-associated, and healthcare-associated pneumonia. Am J Respir Crit Care Med 2005;171(4):388-416.

2. Rea-Neto A, Youssef NCM, Tuche F, Brunkhorst F, Ranieri VM, Reinhart K, Sakr Y. Diagnosis of ventilator-associated pneumonia: a systematic review of the literature. Crit Care 2008;12(2):R56.

3. Kollef MH, Sherman G, Ward S, Fraser VJ. Inadequate antimicrobial treatment of infections: a risk factor for hospital mortality among critically ill patients. Chest 1999;115(2):462-474.

4. Luna CM, Aruj P, Niederman MS, Garzón J, Violi D, Prignoni A, et al. Appropriateness and delay to initiate therapy in ventilatorassociated pneumonia. Eur Respir J 2006;27(1):158-164.

5. Jacobs JA, De Brauwer EI, Ramsay G, Cobben NA, Wagenaar SS, van der Ven AJ, et al. Detection of non-infectious conditions mimicking pneumonia in the intensive care setting: usefulness of bronchoalveolar fluid cytology. Respir Med 1999;93(8):571-578.

6. Corley DE, Kirtland SH, Winterbauer RH, Hammar SP, Dail DH, Bauermeister DE, Bolen JW. Reproducibility of the histologic diagnosis of pneumonia among a panel of four pathologists: analysis of a gold standard. Chest 1997;112(2):458-465.

7. Johanson WG Jr, Pierce AK, Sanford JP, Thomas GD. Nosocomial respiratory infections with gram-negative bacilli. The significance of colonization of the respiratory tract. Ann Intern Med 1972;77(5): 701-706.

8. Fàbregas N, Ewig S, Torres A, El-Ebiary M, Ramirez J, de La Bellacasa JP, et al. Clinical diagnosis of ventilator associated pneumonia revisited: comparative validation using immediate post-mortem lung biopsies. Thorax 1999;54(10):867-873.

9. Pugin J, Auckenthaler R, Mili N, Janssens JP, Lew PD, Suter PM. Diagnosis of ventilator-associated pneumonia by bacteriologic analysis of bronchoscopic and nonbronchoscopic "blind" bronchoalveolar lavage fluid. Am Rev Respir Dis 1991;143(5 Pt 1):1121-1129.

10. Zilberberg MD, Shorr AF. Ventilator-associated pneumonia: the clinical pulmonary infection score as a surrogate for diagnostics and outcome. Clin Infect Dis 2010;51(Suppl 1):S131-S135.

11. Magill SS, Rhodes B, Klompas M. Improving ventilator-associated event surveillance in the National Healthcare Safety Network and addressing knowledge gaps: update and review. Curr Opin Infect Dis 2014;27(4):394-400.

12. Golde DW, Drew WL, Klein HZ, Finley TN, Cline MJ. Occult pulmonary haemorrhage in leukaemia. BMJ 1975;2(5964):166-168.

13. Fartoukh M, Maitre B, Honoré S, Cerf C, Zahar JR, Brun-Buisson C. Diagnosing pneumonia during mechanical ventilation: the clinical pulmonary infection score revisited. Am J Respir Crit Care Med 2003;168(2):173-179.

14. Pham TN, Neff MJ, Simmons JM, Gibran NS, Heimbach DM, Klein MB. The clinical pulmonary infection score poorly predicts pneumonia in patients with burns. J Burn Care Res 2007;28(1):76-79.

15. Luyt CE, Chastre J, Fagon JY. Value of the clinical pulmonary infection score for the identification and management of ventilatorassociated pneumonia. Intensive Care Med 2004;30(5):844-852.

16. Jung B, Embriaco N, Roux F, Forel JM, Demory D, Allardet-Servent J, et al. Microbiogical data, but not procalcitonin improve the accuracy of the clinical pulmonary infection score. Intensive Care Med 2010;36(5):790-798.

17. Ramirez P, Garcia MA, Ferrer M, Aznar J, Valencia M, Sahuquillo $\mathrm{JM}$, et al. Sequential measurements of procalcitonin levels in diagnosing ventilator-associated pneumonia. Eur Respir J 2008;31(2): 356-362.

18. Croce MA, Swanson JM, Magnotti LJ, Claridge JA, Weinberg JA, Wood GC, et al. The futility of the clinical pulmonary infection score 


\section{BRONCHOSCOPY AND BAL IN EARLY Diagnosis OF VAP}

in trauma patients. J Trauma 2006;60(3):523-527; discussion 527528.

19. Shan J, Chen HL, Zhu JH. Diagnostic accuracy of clinical pulmonary infection score for ventilator-associated pneumonia: a meta-analysis. Respir Care 2011;56(8):1087-1094.

20. Choi SH, Hong SB, Hong HL, Kim SH, Huh JW, Sung H, et al. Usefulness of cellular analysis of bronchoalveolar lavage fluid for predicting the etiology of pneumonia in critically ill patients. PLoS One 2014;9(5):e97346.

21. Stolz D, Stulz A, Müller B, Gratwohl A, Tamm M. BAL neutrophils, serum procalcitonin, and C-reactive protein to predict bacterial infection in the immunocompromised host. Chest 2007;132(2):504514.

22. Sternberg RI, Baughman RP, Dohn MN, First MR. Utility of bronchoalveolar lavage in assessing pneumonia in immunosuppressed renal transplant recipients. Am J Med 1993;95(4):358-364.

23. Huh JW, Lim CM, Koh Y, Oh YM, Shim TS, Lee SD, et al. Diagnostic utility of the soluble triggering receptor expressed on myeloid cells-1 in bronchoalveolar lavage fluid from patients with bilateral lung infiltrates. Crit Care 2008;12(1):R6.

24. Tsangaris I, Lekka ME, Kitsiouli E, Constantopoulos S, Nakos G. Bronchoalveolar lavage alterations during prolonged ventilation of patients without acute lung injury. Eur Respir J 2003;21(3):495-501.

25. Nakos G, Kitsiouli EI, Tsangaris I, Lekka ME. Bronchoalveolar lavage fluid characteristics of early intermediate and late phases of ARDS: alterations in leukocytes, proteins, PAF and surfactant components. Intensive Care Med 1998;24(4):296-303.

26. Nakos G, Tsangaris H, Liokatis S, Kitsiouli E, Lekka ME. Ventilator-associated pneumonia and atelectasis: evaluation through bronchoalveolar lavage fluid analysis. Intensive Care Med 2003;29(4): 555-563.
27. Nseir S, Di Pompeo C, Pronnier P, Beague S, Onimus T, Saulnier F, et al. Nosocomial tracheobronchitis in mechanically ventilated patients: incidence, aetiology and outcome. Eur Respir J 2002;20(6): 1483-1489.

28. Koenig SM, Truwit JD. Ventilator-associated pneumonia: diagnosis, treatment, and prevention. Clin Microbiol Rev 2006;19(4):637-657.

29. Craven DE, Hjalmarson KI. Ventilator-associated tracheobronchitis and pneumonia: thinking outside the box. Clin Infect Dis 2010; 51(Suppl 1):S59-S66.

30. Timsit JF, Misset B, Azoulay E, Renaud B, Garrouste-Orgeas M, Carlet J. Usefulness of airway visualization in the diagnosis of nosocomial pneumonia in ventilated patients. Chest 1996;110(1):172179.

31. Knaus WA, Draper EA, Wagner DP, Zimmerman JE. APACHE II: a severity of disease classification system. Crit Care Med 1985; 13(10):818-829.

32. Oh TE, Hutchinson R, Short S, Buckley T, Lin E, Leung D. Verification of the Acute Physiology and Chronic Health Evaluation scoring system in a Hong Kong intensive care unit. Crit Care Med 1993;21(5):698-705.

33. Escarce JJ, Kelley MA. Admission source to the medical intensive care unit predicts hospital death independent of APACHE II score. JAMA 1990:264(18):2389-2394.

34. Marquette CH, Copin MC, Wallet F, Neviere R, Saulnier F, Mathieu $\mathrm{D}$, et al. Diagnostic tests for pneumonia in ventilated patients: prospective evaluation of diagnostic accuracy using histology as a diagnostic gold standard. Am J Respir Crit Care Med 1995;151(6): 1878-1888.

35. Rouby JJ, Martin De Lassale E, Poete P, Nicolas MH, Bodin L, Jarlier V, et al. Nosocomial bronchopneumonia in the critically ill: histologic and bacteriologic aspects. Am Rev Respir Dis 1992;146(4): 1059-1066. 